\title{
INFLUENCE OF PREHEATING ON MECHANICAL AND SURFACE PROPERTIES OF NANOCERAMIC RESIN COMPOSITES
}

\author{
Radwa Ibrahim Eltoukhy*, Ali Atef Elkaffas* and Salah Hasab Mahmoud ${ }^{* *}$
}

\begin{abstract}
Objective: To assess the influence of preheating on microhardness and surface roughness of nanoceramic resin composite.

Methods: Forty disc-shaped specimens of nanoceramic resin composite Ceram X Duo (Dents ply De Trey, Konstanz, Germany) were made using a mold and then randomly assigned into two groups (with and without preheating where $\mathrm{n}=20$ ). Each group was subdivided according to the test into two subgroups $(n=10)$. Vickers hardness measurements for the top and bottom surfaces of the specimens were evaluated by tester machine and surface Roughness (Ra) was assessed using the Atomic Force Microscope.
\end{abstract}

Results: Results of both tests showed no significant difference among specimens either preheated or not. Nevertheless, microhardness results revealed significant difference if top surfaces compared to the bottom ones either the specimens were preheated or not. Surface roughness results exhibited no significant difference among the preheated and non-preheated specimens.

Conclusion: Preheating had a certain effect on the mechanical and surface properties of nanoceramic resin composite.

KEYWORDS: Preheating; nanoceramic composite; microhardness; surface roughness

Clinical significance: Preheating can be clinically beneficial for promoting the manipulation, marginal sealing, and surface features of nanoceramic resin composite.

* Clinical Assistant Professor, Operative Dentistry Dept, Faculty of Dentistry, Mansoura University, Egypt

** Clinical Professor and Chairman of Operative Dentistry Dept, Faculty of Dentistry, Mansoura University, Egypt 


\section{INTRODUCTION}

Resin composite preheating has attained approval by the clinicians to improve manipulation, application and sculpture processes ${ }^{1}$. Also, preheating has a crucial impact on the polymerization process $^{2}$ where, high polymerization temperature improves the monomers movability and ameliorates the total conversion. This can be the reason of the development of resin composite properties especially mechanical and surface ones ${ }^{3}$.

The mechanical properties of resin composites depend on their composition and microstructure ${ }^{4}$. Appropriate clinical execution and improved mechanical characteristics of resin composites have made them further favorable for restoration of posterior teeth ${ }^{5}$. Regardless of enhanced mechanical characteristics, bulk fracture is believed to be a major failure of resin composite restorations ${ }^{6}$.

Clinicians may use the preheating process of resin composite for improving its handling characteristics and mechanical properties ${ }^{7}$. Hence, the mechanical characteristics of resin composite after preheating must be assessed so as to understand the influence of warming on the capability of resin composite to withstand the masticatory forces without fracture.

Preheating results in former investigations were unclear, and sometimes contradictory ${ }^{8,9}$. Munoz et $a l .{ }^{8}$ showed that resin composites warming may enhance their hardness. However, Osternack et al. ${ }^{9}$ mentioned that resin composite hardness was not affected by the preheating process.
The accessible information on the influence of the preheating process of resin composite on its microhardness and surface roughness are deficient, and yet indecisive. Subsequently, the goal of this research was to assess the impact preheating of resin composite on microhardness and surface roughness of a nanoceramic resin composite.

\section{MATERIALS AND METHODS}

Nanoceramic resin composite Ceram $\mathrm{X}$ Duo with shade of A2 (Dents ply De Trey, Konstanz, Germany) (Table 1) was used to fabricate Forty discshaped specimens by a Teflon mold with dimensions of $10 \mathrm{~mm}$ diameter and $2 \mathrm{~mm}$ thickness. These discshaped specimens were randomly assigned into two groups (preheated and without preheating where $\mathrm{n}=20$ ). Each group was subdivided according to the test (microhardness and surface roughness) into two subgroups $(\mathrm{n}=10)$.

An appliance known as Therma-flo ${ }^{\mathrm{TM}}$ composite warming kit (Vista, Wisconsin, USA) was used regarding to the manufacturer's guidance for resin composite preheating before application. It was turned on up till it come to $68^{\circ} \mathrm{C}$. The resin composite cartridge was put within the heating device for a duration of 5 min to gain the heat of the appliance. After that, the cartridge was brought out and resin composite was put directly within the mold which was applied on a Mylar strip above a glass slab.

Later on, resin composite was capped with one more Mylar strip, compressed by a glass slide for

TABLE (1) Materials used in the study

\begin{tabular}{lllll}
\hline Restorative System & Manufacturer & Matrix & Filler & Filler Degree \\
\hline Ceram X Duo & (Dents ply De Trey, & Methacrylate modified & Ba-Al-borosilicate & $76 \mathrm{Wt} \%$. \\
& Konstanz, Germany) & polysiloxane, dimethacrylate & glass, filler (1-1.5 m), & \\
& & resin, fluorescence pigment, & silicon dioxidenanofiller \\
& & UV stabilizer, stabilizer, & $(10 \mathrm{~nm})$ & \\
& & & \\
& & camphorquinone, ethyl- & \\
& & 4(dimethylamino)benzoate & & \\
\hline
\end{tabular}


forcing out the overflow material and subjected to light-cure unit for $10 \mathrm{~s}$. (Monitex BlueLEX ${ }^{\mathrm{TM}}$ GT1200, New Taipei City, Taiwan). The mold, glass slabs and the mylar strips were heated to $37^{\circ} \mathrm{C}$ prior the resin composite application. The specimens were finished and polished using Enhance and PoGo kits (Dentsply Caulk, Milford, DE, USA) and then stored in distilled water in an incubator at $37^{\circ} \mathrm{C}$ for $24 \mathrm{~h}$.

\section{Microhardness Test}

Vickers hardness measurements of the top and bottom surfaces of the specimens were done using microhardness testing machine (Tukon 1102, Buehler,Uzwil,Switzerland) through the application of a load $(100 \mathrm{~g})$ for $10 \mathrm{~s}$. Three indentations with interspace of $1 \mathrm{~mm}$ were picked for every surface and the mean value was evaluated.

\section{Surface Roughness Test}

Surface roughness assessment $(\mathrm{Ra})$ was gained using the Atomic Force Microscope (Autoprobe CP, Thermo-microscopes, Veeco Digital Instruments, Santa Barbra, Calif., USA) in 'contact' mode. Five various regions were chosen to have different images which can be scanned by software (Nanoscope v616r1, Veeco Metrology Group and WSxM 4.0 Develop 11.1, Nanotec Electronica, TreaCantas, Spain) and $\mathrm{Ra}$ assessments were demonstrated as the means $\pm \mathrm{SD}$.

\section{Statistical analysis}

The Shapiro-Wilk test at $a=0.05$ was used to assure the normal distribution of the results. The collected data was analyzed using independent sample t-test at $\mathrm{a}=0.05$ (IBM SPSS Statistics 21.0 software, IBM Chicago, IL, USA).

\section{RESULTS}

Microhardness and surface roughness mean values are mentioned in Tables 2, 3. Shapiro-Wilk test revealed that the results for both tests followed a normal distribution pattern $(\mathrm{p}>0.05)$. T-tests showed no significant difference among specimens either preheated or not for both tests $(p>0.05)$. While, results of microhardness test revealed significant differences between the top surfaces and bottom ones for both groups either preheated or not $(\mathrm{p}<0.05)$. The preheated specimens showed elevated surface roughness mean values (Fig.1) than nonheated ones (Fig.2) but, no significant difference between them was detected $(\mathrm{p}>0.05)$.

TABLE (2). Vickers hardness (VHN) mean values (Standard deviations) achieved in nonpreheated and preheated modes.

\begin{tabular}{lccc}
\hline Resin composite & \multicolumn{2}{c}{ Temperatures } \\
\cline { 2 - 4 } & & Non-heated & Preheated \\
& & $24^{\circ} \mathrm{C}$ & $68^{\circ} \mathrm{C}$ \\
\hline \multirow{2}{*}{ Ceram X Duo } & Top & $70.19 \pm 2.74$ & $70.06 \pm 1.77$ \\
\cline { 2 - 4 } & Bottom & $49.65 \pm 5.80$ & $51.27 \pm 3.16$ \\
\hline
\end{tabular}

The values are shown as mean \pm standard deviation.

TABLE (3). Fracture toughness (MPa) mean values (Standard deviations) achieved in nonpreheated and preheated modes.

\begin{tabular}{lcc}
\hline \multirow{2}{*}{ Resin composite } & \multicolumn{2}{c}{ Temperatures } \\
\cline { 2 - 3 } & $\begin{array}{c}\text { Non-heated } \\
24^{\circ} \mathrm{C}\end{array}$ & $\begin{array}{c}\text { Preheated } \\
68^{\circ} \mathrm{C}\end{array}$ \\
\hline Ceram X Duo & $14.39 \pm 1.37$ & $15.67 \pm 2.13$ \\
\hline
\end{tabular}

The values are shown as mean \pm standard deviation, MPa: Mega Pascal

TABLE (4) Surface roughness average $\mathrm{Ra}(\mathrm{nm})$ mean values (Standard deviations) achieved in non-preheated and preheated modes by AFM.

\begin{tabular}{lcc}
\hline \multirow{2}{*}{ Resin composite } & \multicolumn{2}{c}{ Temperatures } \\
\cline { 2 - 3 } & $\begin{array}{c}\text { Non-heated } \\
24^{\circ} \mathrm{C}\end{array}$ & $\begin{array}{c}\text { Preheated } \\
68^{\circ} \mathrm{C}\end{array}$ \\
\hline Ceram X Duo & $7.05 \pm 1.4$ & $9.14 \pm 2.06$ \\
\hline
\end{tabular}

The values are shown as mean \pm standard deviation 


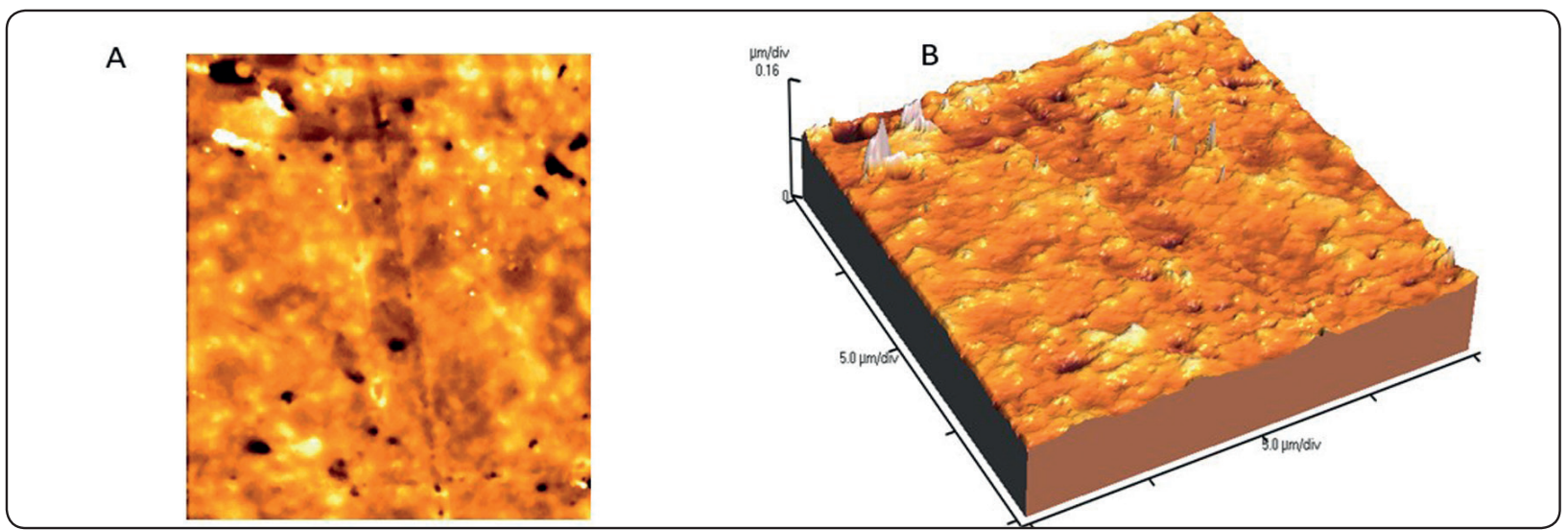

Fig. (1) AFM image of non-heated Ceram X Duo resin composite (A) 2D image; (B) 3D image

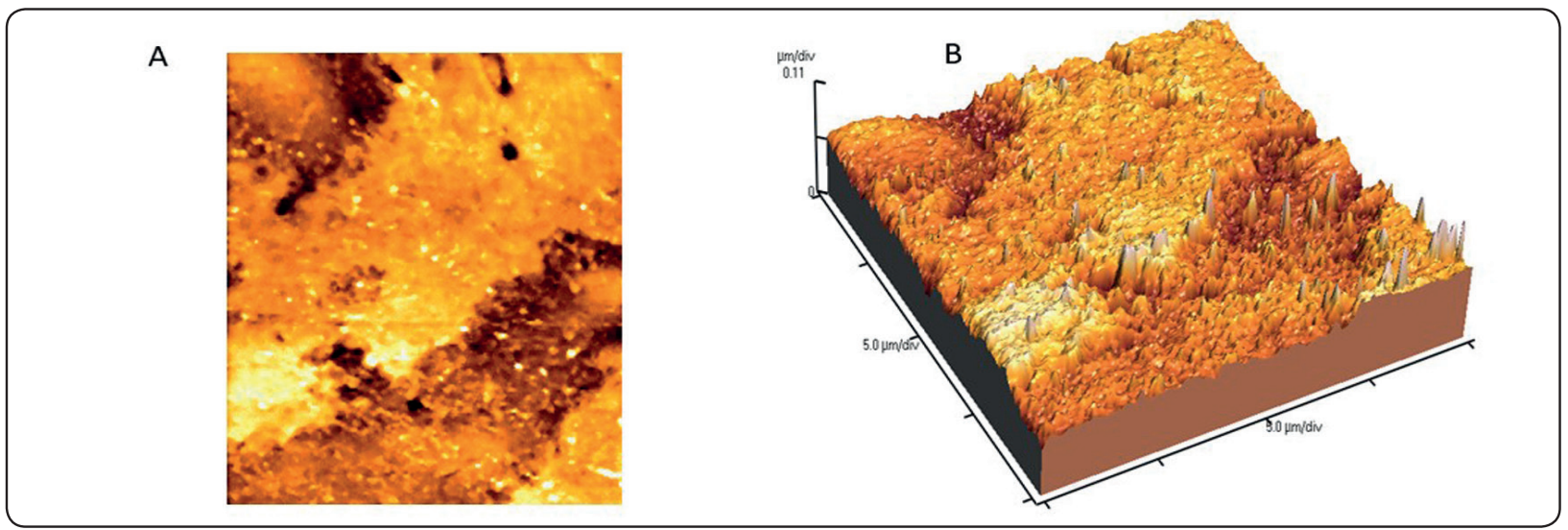

Fig. (2) AFM image of preheated Ceram X Duo resin composite (A) 2D image; (B) 3D image

\section{DISCUSSION}

Preheating is responsible for decreasing the viscosity of packable resin composites and giving them additional flowable state to be injected directly into the prepared cavity instead of packing by hand instruments ${ }^{10}$ and obtained better mechanical and surface properties ${ }^{11}$. Earlier researches showed that increasing the temperature of resin composite leads to lower viscosity and better hardness ${ }^{12,13}$. While, the current research revealed that the hardness of nanoceramic resin composite was not influenced by the warming method.

Hardness assessment is a technique for estimation the degree of conversion in resin composite. The top surfaces of the specimens revealed higher microhardness in comparison to the bottom ones, this was due to light was declined because it moved via resin composite during the curing procedure.

Considerable difference was detected in viscosity of various resin composites due to preheating, this can be explained by the great diversity in composition, chemistry and filler load. Increased molecular weight and high ability for hydrogen bonding, resin composite viscosity will be raised ${ }^{14}$. In addition, the chains of polymers converted into further twisted form by raising filler load owing to excess chain extension and forming excess ramifications, leading to elevated viscosity ${ }^{14}$. Furthermore, these barriers can be overcame by warming process through yielding adequate energy so as to allow molecules movement in a minimal drifting manner ${ }^{14}$. 
Surface roughness results of this research revealed no significant differences among specimens if preheated or not. While, preheated group manifested somewhat higher values. The nanoceramic resin composite involves nanofillers joined with nanoclusters. Nanofillers are separated and nonconglomerated fillers ${ }^{15}$. The nanoclusters raise the filler capacity and physical characteristics of the resin composite. So, the regular allocation of precured particles within the matrix is the cause of not being influenced by the warming process ${ }^{15}$.

\section{CONCLUSION}

Preheating had a certain effect on the mechanical and surface properties of nanoceramic resin composite.

\section{REFERENCES}

1. Sakaguchi RL. Commentary: clinically relevant issues related to preheating composites. J Esthet Restor Dent. 2006;18:351-351.

2. Daronch M, Rueggeberg F, De Goes M, Giudici R. Polymerization kinetics of pre-heated composite. J Dent Res. 2006;85:38-43.

3. Trujillo M, Newman SM, Stansbury JW. Use of near-IR to monitor the influence of external heating on dental composite photopolymerization. Dent Mater. 2004;20:766-777.

4. Al-Sharaa KA, Watts DC. Stickiness prior to setting of some light cured resin-composites. Dent Mater. 2003;19:182-187.

5. Cramer N, Stansbury J, Bowman C. Recent advances and developments in composite dental restorative materials. J Dent Res. 2011;90:402-416.

6. Sarrett DC. Clinical challenges and the relevance of materials testing for posterior composite restorations. Dent Mater. 2005;21:9-20.

7. Tantbirojn D, Chongvisal S, Augustson DG, Versluis A. Hardness and postgel shrinkage of preheated composites. Quintessence Int. 2011;42:e51-e59.

8. Munoz CA, Bond PR, Sy-Munoz J, Tan D, Peterson J. Effect of pre-heating on depth of cure and surface hardness of light-polymerized resin composites. Am J Dent. 2008;21:215-222.
9. Osternack F, Caldas D, Almeida J, Souza EM, Mazur RF. Effects of preheating and precooling on the hardness and shrinkage of a composite resin cured with QTH and LED. Oper Dent. 2013;38:e50-e57.

10. Deb S, Di Silvio L, Mackler HE, Millar BJ. Pre-warming of dental composites. Dent Mater. 2011;27:e51-e59.

11. Uctasli MB, Arisu HD, Lasilla LV, Valittu PK. Effect of preheating on the mechanical properties of resin composites. Eur J Dent. 2008;2:263-268.

12. Fróes-Salgado NR, Silva LM, Kawano Y, Francci C, Reis A, Loguercio AD. Composite pre-heating: effects on marginal adaptation, degree of conversion and mechanical properties. Dent Mater. 2010;26:908-914.

13. Mohammadi N, Jafari-Navimipour E, Kimyai S, Ajami AA, Bahari M, Ansarin M. Effect of pre-heating on the mechanical properties of silorane-based and methacrylatebased composites. J Clin Exp Dent. 2016;8:e373-e378.

14. Mahmoud SH, Ahmed ME, Mahmoud KM, Grawish ME, Zaher AR. Effects of phosphoric acid concentration and etching duration on enamel and dentin tissues of uremic patients receiving hemodialysis: an AFM study. J Adhes Dent. 2012;14:215-221.

15. Da Costa JB, Hilton TJ, Swift J, Edward J. Preheating composites. J Esthet Restor Dent. 2011;23:269-275.

16. Osternack FHR, Caldas DBdM, Rached RN, Vieira S, Platt JA, Almeida JBD. Impact of refrigeration on the surface hardness of hybrid and microfilled composite resins. Braz Dent J. 2009;20:42-47.

17. Lovelh L, Newman S, Bowman C. The effects of light intensity, temperature, and comonomer composition on the polymerization behavior of dimethacrylate dental resins. J Dent Res. 1999;78:1469-1476.

18. Prasanna N, Reddy YP, Kavitha S, Narayanan LL. Degree of conversion and residual stress of preheated and roomtemperature composites. Indian J Dent Res. 2007;18:173.

19. Daronch M, Rueggeberg FA, Moss L, De Goes MF. Clinically relevant issues related to preheating composites. J Esthet Restor Dent. 2006;18:340-350.

20. Bouschlicher M, Rueggeberg F, Wilson B. Correlation of bottom-to-top surface microhardness and conversion ratios for a variety of resin composite compositions. Oper Dent. 2004;29:698-704.

21. David JR, Gomes OM, Gomes JC, Loguercio AD, Reis A. Effect of exposure time on curing efficiency of polymerizing units equipped with light-emitting diodes. J Oral Sci. 2007;49:19-24. 
22. Rueggeberg F, Caughman WF, Curtis J. Effect of light intensity and exposure duration on cure of resin composite. Oper Dent. 1994;19:26-27.

23. Calheiros FC, Daronch M, Rueggeberg FA, Braga RR. Degree of conversion and mechanical properties of a BisGMA: TEGDMA composite as a function of the applied radiant exposure. Journal of Biomedical Materials Research Part B: Applied Biomaterials: An Official Journal of The Society for Biomaterials, The Japanese Society for Biomaterials, and The Australian Society for Biomaterials and the Korean Society for Biomaterials. 2008;84:503-509.

24. Loughran GM, Versluis A, Douglas WH. Evaluation of sub-critical fatigue crack propagation in a restorative composite. Dent Mater. 2005;21:252-261.

25. Della Bona A, Anusavice KJ, DeHoff PH. Weibull analysis and flexural strength of hot-pressed core and veneered ceramic structures. Dent Mater. 2003;19:662-669.

26. Chung S, Yap A, Chandra S, Lim C. Flexural strength of dental composite restoratives: Comparison of biaxial and three-point bending test. Journal of Biomedical Materials
Research Part B: Applied Biomaterials: An Official Journal of The Society for Biomaterials, The Japanese Society for Biomaterials, and The Australian Society for Biomaterials and the Korean Society for Biomaterials. 2004; 71:278-283

27. Palin W, Fleming G, Marquis P. The reliability of standardized flexure strength testing procedures for a light-activated resin-based composite. Dent Mater. 2005;21:911-919.

28. Kalachandra S, Sankarapandian M, Shobha H, Taylor D, McGrath J. Influence of hydrogen bonding on properties of BIS-GMA analogues. J Mater Sci: Mater Med. 1997;8:283-286.

29. Shobha H, Sankarapandian M, Kalachandra S, Taylor D, McGrath J. Structure property relationship among novel dental composite matrix resins. J Mater Sci: Mater Med. 1997;8:385-389.

30. Garcia FCP, Wang L, D’Alpino PHP, Souza JBd, Araújo PAd, Mondelli RFdL. Evaluation of the roughness and mass loss of the flowable composites after simulated toothbrushing abrasion. Braz Oral Res. 2004;18:156-161. 